\title{
The Fetal Outcome and Fetal Wastage Pattern among Different Types of Obstetric Fistula at the National Obstetric Fistula Centre, Abakaliki, Nigeria
}

\author{
Kenneth Chinedu Ekwedigwe',2*, Onwe O. Emeka ${ }^{3}$, Isikhuemen E. Maradona4, Iwe Bobby², \\ Azubuike K. Onyebuchi², Obuna Johnson',2, Ezeonu P. Olisaemeka², \\ Onoh C. Robinson ${ }^{2}$, Ekwedigwe P. Ifeanyi ${ }^{2}$ \\ ${ }^{1}$ Clinical Services, National Obstetric Fistula Centre, Abakaliki, Nigeria \\ ${ }^{2}$ Department of Obstetrics and Gynaecology, Alex-Ekwueme Federal University Teaching Hospital, Abakaliki, Nigeria \\ ${ }^{3}$ Department of Paediatrics, Alex-Ekwueme Federal University Teaching Hospital, Abakaliki, Nigeria \\ ${ }^{4}$ Department of Obstetrics and Gynaecology, University of Benin Teaching Hospital, Benin, Nigeria \\ Email: *ekwedigwe@yahoo.com
}

How to cite this paper: Ekwedigwe, K.C., Emeka, O.O., Maradona, I.E., Bobby, I., Onyebuchi, A.K., Johnson, O., Olisaemeka, E.P., Robinson, O.C. and Ifeanyi, E.P. (2020) The Fetal Outcome and Fetal Wastage Pattern among Different Types of Obstetric Fistula at the National Obstetric Fistula Centre, Abakaliki, Nigeria. Open Journal of Obstetrics and Gynecology, 10, 538-545.

https://doi.org/10.4236/ojog.2020.1040048

Received: March 26, 2020

Accepted: April 19, 2020

Published: April 22, 2020

Copyright $\odot 2020$ by author(s) and Scientific Research Publishing Inc. This work is licensed under the Creative Commons Attribution International License (CC BY 4.0).

http://creativecommons.org/licenses/by/4.0/

\begin{abstract}
BACKGROUND: Obstetric Fistula is a major public health problem in developing world. It is associated with a high fetal wastage rate. The objective of this study was to evaluate different types of obstetric fistula and their fetal wastage rate. METHOD: A retrospective population study was done at the National Obstetric Fistula Centre, Abakaliki between $1^{\text {st }}$ January- $31^{\text {st }}$ December, 2016. The calculated minimum sample size was 3 , however, the total number of 203 patients were studied. The case notes of all the women who had obstetric fistula repairs over the period were analyzed. RESULTS: The mean age from this study was $38 \pm 12.1$ years. The fetal wastage rate from this study was $82.76 \%$ while the live birth was $17.24 \%$. Seventy percent of the stillbirth were delivered via SVD, while $11 \%$ of stillbirth were delivered through EmCS. Twelve different types of fistula were identified in this study using anatomical classifications. Large extensive fistula, urethral loss and multiple fistula had the highest fetal wastage of $100 \%$ respectively. This was followed by mid-vaginal fistula (95.7\%), Juxtaurethral fistula 94.4\%, Juxtacervical fistula $88.5 \%$, Intracervical fistula $85.71 \%$, Ureteric fistula $85.71 \%$, Vesicouterine $84.21 \%$, Vault fistula $62.5 \%$. Rectovaginal fistula had the least fetal wastage of $15.79 \%$ and the highest live birth of $84.2 \%$. CONCLUSION: The findings showed a high fetal wastage rate amongst women with obstetric fistula. There was high fetal wastage across different types of obstetric fistula. Rectovaginal fistula had the best outcome in terms of live births.
\end{abstract}




\section{Keywords}

Obstetric Fistula, Fetal Wastage/Stillbirth, Live Birth

\section{Introduction}

Obstetric Fistula is a form of genital fistula resulting from the process of delivery. It is an abnormal communication between the female genital tract and the lower urinary tract forming the urogenital fistula with consequent leakage of urine through the vagina and/or the lower gastro-intestinal tract forming the faecal genital fistula which allows leakage of faeces through the vagina. The commonest of the fistulas is the vesico-vaginal fistula (VVF) [1].

Obstetric fistula is a public health issue in the developing world. It is a major public health concern in Nigeria. It is a disease with tremendous socio-economic and health implications and consequences [2]. It tells the untold story of high rate of maternal mortality in developing countries.

Generally, the obstetric fistula patient is often poor, uneducated, unhappy and abandoned. The disease takes away their dignity and is often associated with great psychological burden. Other associated problems may include infertility, menstrual irregularities, vaginal stenosis dyspareunia, apareunia, difficulty in walking, begging and cheap prostitution [1]. Generally, victims often end up as destitute if the incontinence is not relieved. They are socially, mentally, emotionally and sometimes physically challenged [1].

Obstetric fistula is associated with a high fetal wastage rate, leaving victims in a profound state of despair from childlessness, incontinence and abandonment. Obstetric fistula practice manual in Nigeria reported a fetal wastage rate of $96 \%$ [1].

This childlessness often arose from fetal distress and consequent stillbirth resulting from prolonged obstructed labour, intrapartum neglect and different levels of delays in labour.

The problem with prolonged obstructed labour is that it causes squeeze between the fetal bone and maternal pelvic bone anteriorly and the sacrum posteriorly leading to ischaemia which subsequently leads to necrosis and sloughing off of the tissue thereby causing fistula. The halt in labour progress, the long duration of labour with increase squeeze of the fetal skull results in fetal hypoxia/anoxia and consequent fetal distress which results to stillbirth.

A cross-sectional retrospective study done in Kassala hospital, Sudan showed perinatal mortality of $35.7 \%$ [3]. A retrospective case review study done at Kitovu hospital in Uganda showed stillbirth of $69 \%$ and early neonatal death of $12 \%$. A hospital based cross-sectional study done at Jimma University Teaching Hospital in Ethiopia showed stillbirth rate of $85.7 \%$.

Despite all these findings, few if any study have described the fetal wastage pattern for different types of obstetric fistula. 
The general aim and objective of this study is to evaluate the fetal wastage pattern among different types of obstetric fistula at the National Obstetric Fistula Centre, Abakaliki. The specific objective will be to evaluate the overall fetal wastage pattern for obstetric fistula during the study period and to evaluate specific fetal wastage pattern for different types of obstetric fistulae.

\section{Materials and Method}

A one year retrospective study was conducted at the National Obstetric Fistula Centre, Abakaliki from $1^{\text {st }}$ January 2016 to $31^{\text {st }}$ December 2016. The centre is located in Abakaliki, South-East Nigeria and offers free services to women with genital fistulas. The centre is also a designated research centre for urogenital fistula. Her bed space capacity is 96 .

Sample size: The sample size was calculated using a statistical formula based on the proportion of $0.211 \%$ for women with obstetric fistula from a study by Ijaiya et al. in Ilorin Nigeria [4], and a confidence level set at $95 \%$ with an error margin of 0.05 .

$$
n=Z^{2} p q / e^{2}\left(n=p q /(0.05 / 1.96)^{2}\right)
$$

where:

$n$ is the sample size

1.96 is a known constant (Standard normal deviate corresponding to 95\% confidence level).

$P \quad$ is the proportion of women with OF in a study by ljaiya et al. $=0.211 \%$ $=0.00211$.

$Q \quad$ is $1-P$ (proportion of the persons free from the disease $=0.998$.

$E \quad$ is the error margin $=0.05=0.00211 / 0.000651$.

Calculated minimum sample size $=3.22$. A $10 \%$ attrition rate was allowed giving a total of 5 patients for the minimum sample size. However, the case notes of 203 patients were reviewed during this study period to give a better representation.

Sampling Technique: Population study was done using the case notes of all the patients that were treated in the hospital for the year 2016.

Data collection: The data was collected and analyzed using SPSS version 22.

\section{Ethical Consideration}

Ethical approval was obtained from the ethical committee of the National Obstetric Fistula Centre, located in Abakaliki, for the study. The study adhered to the tenets of Helsinki declaration.

\section{Results}

The mean age from this study is $38 \pm 12.1$ years. Majority of the patients are in the reproductive age group (78.8\%), the highest age range is between 30 - 39 years which is $39.4 \%$, the least age range is $70-79$ years which is $2.9 \%$. Majority of the patients are in a monogamous marriage setting (56.2\%). Most of the pa- 
tients did not have any formal education (24.1\%), while majority had senior secondary education (32.5\%). Majority of the patients are Ibo (73.4\%), followed by Urhobo \& Ibibo (5.4\%) respectively. Majority of the patients are farmers (35\%), which is followed by self employed (32.5\%) (Table 1 ).

Table 1. Socio-demographic variable.

\begin{tabular}{|c|c|c|}
\hline & Frequency $(\mathrm{N}=203)$ & Percentage (\%) \\
\hline \multicolumn{3}{|l|}{ Age } \\
\hline $20-29$ & 51 & 25.1 \\
\hline $30-39$ & 80 & 39.4 \\
\hline $40-49$ & 29 & 14.3 \\
\hline $50-59$ & 20 & 9.9 \\
\hline $60-69$ & 17 & 8.4 \\
\hline $70-79$ & 6 & 2.9 \\
\hline \multicolumn{3}{|l|}{$\operatorname{MEAN}($ Std $)=38 \pm 12.1$} \\
\hline \multicolumn{3}{|l|}{ Marital status } \\
\hline Monogamous & 114 & 56.2 \\
\hline Polygamous & 28 & 13.8 \\
\hline Single & 43 & 21.2 \\
\hline Separated & 9 & 4.4 \\
\hline Widowed & 9 & 4.4 \\
\hline \multicolumn{3}{|l|}{ Level of Education } \\
\hline No formal Education & 49 & 24.1 \\
\hline Primary & 54 & 26.6 \\
\hline Junior Secondary & 11 & 5.4 \\
\hline Senior Secondary & 66 & 32.5 \\
\hline NCE & 6 & 3.0 \\
\hline Tertiary & 17 & 8.4 \\
\hline \multicolumn{3}{|l|}{ Ethnic Group } \\
\hline Hausa & 3 & 1.5 \\
\hline Igbo & 149 & 73.4 \\
\hline Yoruba & 3 & 1.5 \\
\hline Ibibio & 11 & 5.4 \\
\hline Efik & 6 & 2.9 \\
\hline Ogoni & 3 & 1.5 \\
\hline Urhobo/Isoko & 11 & 5.4 \\
\hline Ijaw & 6 & 3.0 \\
\hline Idoma/Igala & 8 & 3.9 \\
\hline Edo/Esan & 3 & 1.5 \\
\hline \multicolumn{3}{|c|}{ Employment/Income source } \\
\hline Unemployed & 26 & 12.8 \\
\hline Farming & 71 & 35.0 \\
\hline Artisan/Petty Trading & 26 & 12.8 \\
\hline Government Worker & 8 & 3.9 \\
\hline Self Employed & 66 & 32.5 \\
\hline Private Sector & 6 & 3.0 \\
\hline
\end{tabular}


The table below showed types of obstetric fistula and the fetal outcome. From the table, the incidence of intracervical fistula was highest (17.2\%), followed by circumferential defect $14.8 \%$. The incidence of RVF was $9.4 \%$. The least was urethral loss $1 \%$. There was high fetal wastage $(82.76 \%)$ amongst the obstetric fistula patients. The fetal wastage was highest with patients with large extensive fistula, Urethral loss and multiple fistula which were $100 \%$ respectively. There was only $15 \%$ fetal wastage rate among women with rectovaginal fistula (Table 2 ).

From Table 3 below, 18 patients had Juxtaurethral fistula, out of which a patient (5.6\%) had a livebirth and 17patients (94.4\%) had stillbirth. Twenty three patients had midvaginal fistula, out of which a patient (4.3\%), had livebirth and 22 patients $(95.7 \%)$ had stillbirth. Thirty five patients had Intracervical Fistula, 5 patients $(14.3 \%)$ had livebirth while 30 patients $(85.8 \%)$ had stillbirth. Nineteen patients had Vesicouterine fistula, 3 (15.8\%) had livebirth, while $16(84.2 \%)$ had stillbirth. Also, for Ureteric fistula, 7 patients were identified, a patient (14.3\%) had livebirth while 6 patients (85.7\%) had stillbirth. Thirteen patients had Large/extensive fistula, all of them (100\%) had stillbirth. Nineteen patients had Rectovaginal fistula, 16 of the patients (84.2\%) had livebirth, while 3 of them (15.8\%) had stillbirth. Two patients had urethral loss and the two (100\%) had stillbirth. Thirty patients had circumferential fistula, 2 of the patients (6.7\%) had livebirth, while 28 patients (93.3\%). Eight patients had vault fistula, out of which 3 (37.5\%) had livebirth, while 5 (62.5\%) had stillbirth. Three patients had multiple fistula, the $3(100 \%)$ had stillbirth.

From the simple bar chart below, intracervical fistula (17.2\%) was the highest, followed by circumferential defect $14.8 \%$. The least was circumferential fistula with urethral loss (1\%) (Figure 1).

Table 2. Types of obstetric fistula and fetal outcome.

\begin{tabular}{ccccc}
\hline \multirow{2}{*}{ Type Of Fistula } & \multicolumn{4}{c}{ Fetal Outcome } \\
\cline { 2 - 5 } & Livebirth & Stillbirth Vag.del & Stillbirth (c/s) & Total (\%) \\
\hline Juxtaurethral/bladder neck & 1 & 13 & 4 & $18(8.9)$ \\
Mid-vaginal & 1 & 20 & 2 & $23(11.3)$ \\
Juxtacervical & 3 & 22 & 1 & $26(12.8)$ \\
Intracervical & 5 & 29 & 1 & $35(17.2)$ \\
Vesicouterine & 3 & 16 & 0 & $19(9.4)$ \\
Ureteric & 1 & 2 & 4 & $7(3.4)$ \\
Large/extensive fistula & 0 & 13 & 0 & $13(6.4)$ \\
Rectovaginal fistula & 16 & 0 & 3 & $19(9.4)$ \\
Urethral loss & 0 & 0 & 2 & $2(1.0)$ \\
Circumferential defect & 2 & 26 & 2 & $30(14.8)$ \\
Vault fistula & 3 & 1 & 4 & $8(3.9)$ \\
Multiple fistula & 0 & 2 & 1 & $3(1.5)$ \\
Total (\%) & $35(17.24)$ & $144(70.94)$ & $24(11.82)$ & $203(100)$ \\
\hline
\end{tabular}


Table 3. Pattern of fetal outcome amongst different types of fistulae.

\begin{tabular}{|c|c|c|c|c|}
\hline \multirow{2}{*}{ Type Of Fistula } & \multicolumn{3}{|c|}{ Fetal Outcome } & \multirow{2}{*}{$\begin{array}{c}\text { Total } \\
(\%)\end{array}$} \\
\hline & Livebirth & Stillbirth Vag.del & Stillbirth $(\mathrm{c} / \mathrm{s})$ & \\
\hline $\begin{array}{c}\text { Juxtaurethral/bladder } \\
\text { neck }\end{array}$ & $1(5.6 \%)$ & $13(72.2 \%)$ & $4(22.2 \%)$ & $18(100)$ \\
\hline Mid-vaginal & $1(4.3 \%)$ & $20(87 \%)$ & $2(8.7 \%)$ & $23(100)$ \\
\hline Juxtacervical & $3(11.5 \%)$ & $22(84.6 \%)$ & $1(3.8 \%)$ & $26(100)$ \\
\hline Intracervical & $5(14.2 \%)$ & $29(83 \%)$ & $1(2.8 \%)$ & $35(100)$ \\
\hline Vesicouterine & $3(15.8 \%)$ & $16(84.2 \%)$ & $0(0.0 \%)$ & $19(100)$ \\
\hline Ureteric & $1(14.3 \%)$ & $2(28.6 \%)$ & $4(57.1 \%)$ & $7(100)$ \\
\hline Large/extensive fistula & $0(0.0 \%)$ & $13(100 \%)$ & $0(0.0 \%)$ & $13(100)$ \\
\hline Rectovaginal fistula & $16(84.2 \%)$ & $0(0.0 \%)$ & $3(15.8 \%)$ & $19(100)$ \\
\hline Urethral loss & $0(0.0 \%)$ & $0(0.0 \%)$ & $2(100 \%)$ & $2(100)$ \\
\hline Circumferential defect & $2(6.7 \%)$ & $26(86.6 \%)$ & $2(6.7 \%)$ & $30(100)$ \\
\hline Vault fistula & $3(37,5 \%)$ & $1(12.5 \%)$ & $4(50 \%)$ & $8(100)$ \\
\hline Multiple fistula & $0(0.0 \%)$ & $2(66.7 \%)$ & $1(33.3 \%)$ & $3(100)$ \\
\hline
\end{tabular}

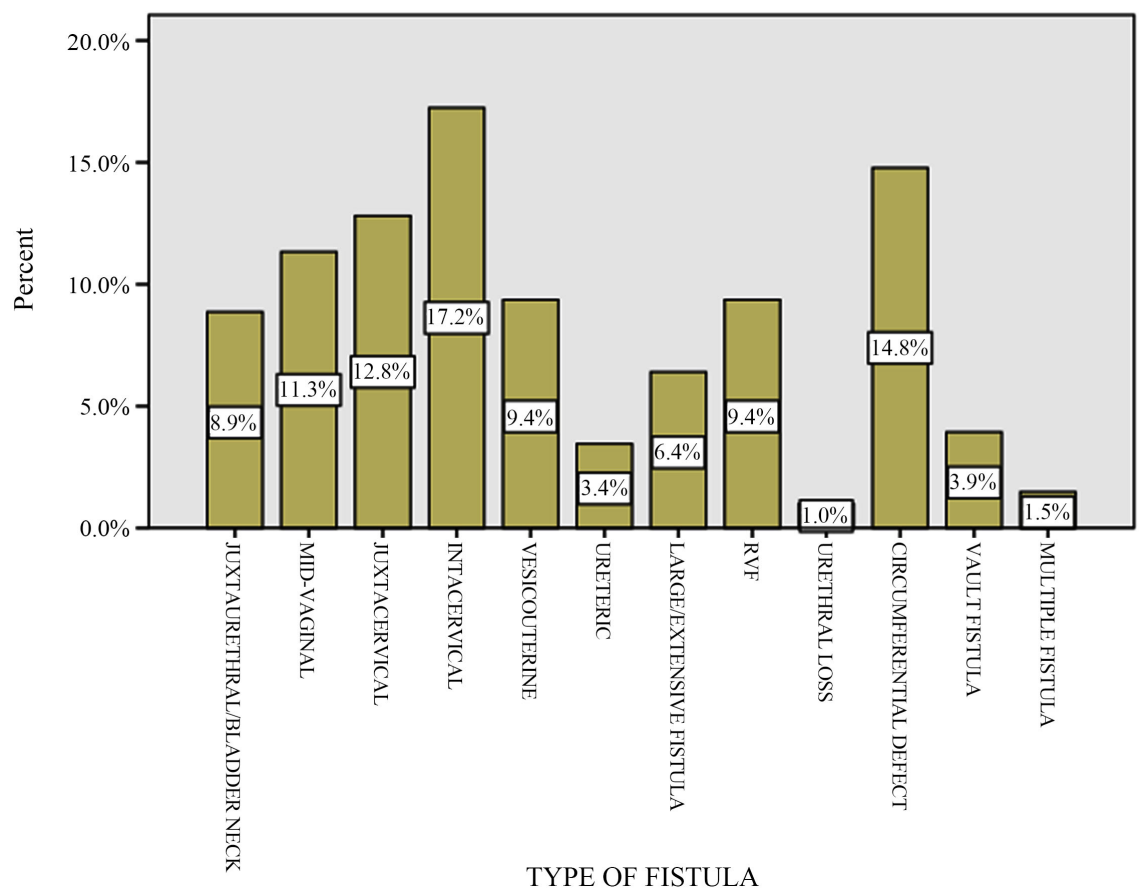

Figure 1. Simple bar chart showing types of obstetric fistula.

\section{Discussion}

The mean age from this study was 38 years. This age falls within the reproductive age group. This falls within the age ranges of related studies done in Abakaliki [5] and Ethiopia [6]. However, it is different from the mean age of 16 years recorded in the North-Central part of Nigeria [7]. 
The fetal wastage from is study was $82.76 \%$ while the livebirth was $17.24 \%$. This is similar to the work done in Ethiopia [6] and Uganda [8]. It is also similar to the documentation in the Obstetric Fistula Manual Doctor's version in Nigeria. However, it is different from the findings in Sudan [3] which was $35.7 \%$. Seventy percent of the stillbirth were delivered via Spontaneous vertex delivery (SVD), while $11 \%$ of the stillbirth were delivered through Emergency Caesarean Section (EMCS). This is because most patients with prolonged obstructed labour present with intrauterine fetal death (IUFD), hence, the preferred choice of SVD.

Twelve different types of fistula were identified in this study using anatomical classifications by Lawson. This is similar to the findings in the studies done at Abakaliki, Kano, and Sokoto in Nigeria. It is also similar to studies done in Sudan and Ethiopia. Large extensive fistula, urethral loss and multiple fistula had the highest fetal wastage of $100 \%$ respectively. This could suggest that the magnitude of tissue loss and organ damage connotes severity and adverse fetal outcome. The fetal wastage in patients with mid-vaginal fistula was $95.7 \%$. This was followed by Juxtaurethral fistula $94.4 \%$, Juxtacervical fistula $88.5 \%$, Intracervical fistula $85.8 \%$, Ureteric fistula $85.7 \%$, Vesicouterine $84.2 \%$, Vault fistula $62.5 \%$. Rectovaginal fistula had the least fetal wastage of $15.8 \%$ and the highest livebirth of $84.2 \%$. This could be due to reduced impact on the fetus in RVF because of the presence of more maternal soft tissues and reduced maternal bony impact [5].

\section{Conclusion}

The findings showed a high fetal wastage rate amongst women with obstetric fistula. There is high fetal wastage across different types of obstetric fistula. Rectovaginal fistula had the best outcome in terms of livebirths.

\section{Conflicts of Interest}

The authors wish to express that there was no conflict of interest and that the research was not funded by any grant.

\section{References}

[1] FMOH (2011) Standard of Practice on Obstetric Fistula in Nigeria Doctors' Version.

[2] Kabir, M., Iliyasu, Z., Abubakar, I.S. and Umar, U.I. (2003) Medico-Social Problems of Patients with Vesicovaginal Fistula in Murtala Mohammed Specialist Hospital, Kano. Annals of African Medicine, 2, 54-57.

[3] Ali, A.A. and Adam, I. (2010) Maternal and Perinatal Outcomes of Obstructed Labour in Kassala Hospital, Sudan. Journal of Obstetrics and Gynaecology, 30, 376-377. https://doi.org/10.3109/01443611003672096

[4] Ijaiya, M.A., Rahman, A.G., Aboyeji, A.P., Olatinwo, A.W.O., Esuga, S.A. and Ogah, O.K. (2010) Vesicovaginal Fistula: A Review of Nigerian Experience. West African Journal of Medicine, 29, 293-298. https://doi.org/10.4314/wajm.v29i5.68247

[5] Ekwedigwe, K.C., Daniyan, A.B.C., Isikhuemen, M.E, Sunday-Adeoye, I., Yakubu, E.N., Eliboh, M.O., Lengmang, S. and Mbamalu, S. (2017) Management of Rectova- 
ginal Fistulas at the National Obstetric Fistula Centre, Abakaliki over a 5-Year Period. Journal of Health, Medicine and Nursing, 41.

[6] Sori, D.A., Azale, A.W. and Gemeda, D.H. (2016) Characteristics and Repair Outcome of Patients with Vesicovaginal Fistula Managed in Jimma University Teaching Hospital, Ethiopia. BMC Urology, 16, 41.

https://doi.org/10.1186/s12894-016-0152-8

[7] Ahmed, Z.D., Abdullahi, H.M., Yola, A.I. and Yakasai, I.A. (2013) Obstetric Fistula Repairs in Kano, Northern Nigeria. The Journey so far. Ann Trop Med Public Health, 6, 545-548. https://doi.org/10.4103/1755-6783.133712

[8] McCurdie, F.K., Moffatt, J. and Jones, K. (2018) Vesicovaginal Fistula in Uganda. Journal of Obstetrics and Gynaecology, 38, 822-827.

https://doi.org/10.1080/01443615.2017.1407301 